DEPARTAMENTO DF INDESTRIA, INSPECAO D CONSTERASAUU DOS

PRODITOS AIIMISNICIOS DE OLICLM ANIMAI.

Dirctor: I'rof. Dr. ['ascliwal .Hucciolo

\title{
RECONHECIMENTO DA NATUREZA DAS MANCHAS DE COLORAÇÃO VERDE EM PRODUTOS DE SALSICHARIA (")
}

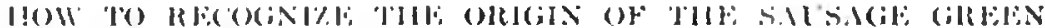 \\ DISTOLOMATION
}

\author{
1. S. Sirno:meth \\ (). М. Bлнкито \\ Issistente \\ 'Tecomologiats
}

Na tecnolngia de carnes. problema dos mais sérios pelo significado ecrno. mico de que muitas vêzes se reveste é, sem dúvida, aquêle constituido pelo aparecimento de colorações anormais cun produtos de salsicharia. Isto porque se, $\mathrm{cm}$ alguns casos, a modificação de coj traduz profundas alteraçōes dos produtos que assim se tornam prejudiciais à sande do consumidor, o mais das vêzes a rôr anormal, mesmo sem afetar diretamente a salubridade do alimento, êste ainda assim deve ser retirado do comércio porque causa repugnancia ao público.

As causas determinantes da modíficaçio de cồ em produlos de salsicharia podem, de início, ser de nature\% quimica ou microbiana, embora no curso do processo nem sempre se possa nitidamente separá-las. F' que, como adiante ve. remos. mesmo quando a alteração se prende à ação de cerlas bactérias: ainda acsim reconhece-se a concomitância de fenômenos químicos.

Nesta comunicação deixaremos de lado as alteraçōes de côr originadas quer pelo processo putrefativo, quer pela presença de cerlos sáis de metais (cobre, ferro, aluminio c outros), ocupando-nos apenas da coloração verde, que está ligada. de um lado, a presença de bactérias. algumas do gênero lactobacillus a. de outro, a pigmento normalmente formado pelo ixido nitrico nais hemo. rromogênio e que resulta da açăo do (alor sôbre carne preparada com salmoura rontendo nitralos ou nitritos.

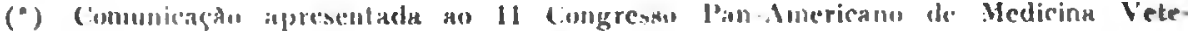

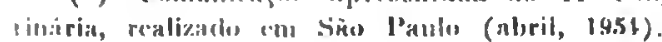


Fimbora nāo se conheça definitivamente o mecanismo de produção da côr vcrde, acredita-se que certos menbros do gênero laclobucillus drlemine"n indiretamente o fenômeno, porque, não possuindo catalase, conseguem, cutrelanto, oxidar certas substancias da carne e formar peróxido de hidrogênio. cm condiçōes de aerobiose, servindo-se do oxigênio atmosférico que funciona romon re. ceptor de hidrogênio. Pois hem. nos produlos de salsicharia cozidos. o preri. xido de hidrogênio assim formado, oxidando o pigmmento que a o resultado da combinação do óxido nítrico mais o hemocromogênio, detcrmina o aparecimento de compostos de natureza ainda mal conhecida que conferem côr verde ancormal aos produtos.

Na prática, quando se apresentam produtos de sal-icharial mostrando manchas de coloração verde, a preocupação primeira do industrial i seber a que alribuir a alteração, pôslo que como atrás dissemos. à origem microbiana sta cồ ve:de deve-se juntar aquela devida a sáis de cerlos melais.

A presente commnicação refere-se precisamente à disulgação de um mein de cultura por nos idealizado que permite, em pouras horas, estabelecer a na. tureza das manchas de côr verde, isto é, se a origen da alteração deve ser atribuida a una causa microbiana ou química, fato cuja importancia reside (m) apontar qual a trilha a seguir no estudo posterior da alteração. Por autro lado, csta primeira indicaça poderá orientar o industrial quanto dis medida: que inediatamente dese tomar com " abjetivo de afastar as causas delerminan. tes do defeito.

Como vimos anteriormente, entre os microorerani-mos responsácés par lal anormalidade de côr, encontram-se representantes do gênero lachobncillus. memhros do grupo helerofermentativo, exigentes. de dificil coltion e i=colansonto. crescendo mal e ragarosamente nos meios de cullura comuns.

Interessados no estudo de um grupo de germes isolados de manchils verdes encontradas em presuntos, csharramos con grandes dificuldades no exlucio to sua biologia co razão de nẫo se aclaplarem aos terrenos comuns de cultion. Fimpregamos então o mein cuja composiçäo está relatada no quadro l c que. além de fornecer bom crescimento, determinava o aparecimento do piymento verde, entre 3.12 horas $\mathrm{cm}$ colufa a $30.31^{\circ} \mathrm{C}$, mantida em grílu elevado do. umidade.

Sistas condiğess, no miximo em 12 horas, ulilizande o mein de cultura por nis apontab, pole-se reconbecer se a origem de manchas verdes apresen. tadas am produtos de salsirharia leve ser atribuida a una causa microbiana on

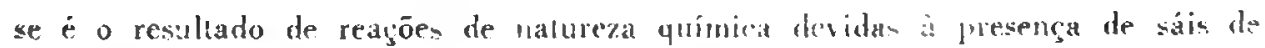
netais como rohre, ferrn, aluminio e outros. 


\section{QUADRO I}

\begin{tabular}{|c|c|}
\hline Conposiçio do meio de cultura & \\
\hline 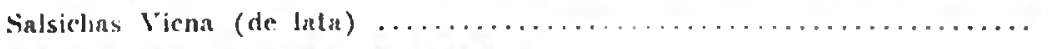 & $3(k) \mathrm{K}$ \\
\hline Salmoura da própria lata de salsichas. & $100 \mathrm{ml}$ \\
\hline 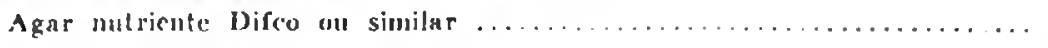 & $2.5 \mathrm{R}$ \\
\hline Henuglubinn Difea ou similar .......... & 2 म \\
\hline Fixtrato de levedos Difco on similar .. & 3 少 \\
\hline 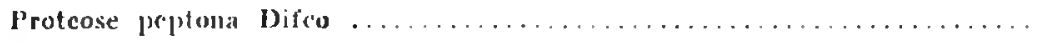 & $g$ \\
\hline I'ryptoun l)if('o ....... & $5 \mathrm{~g}$ \\
\hline 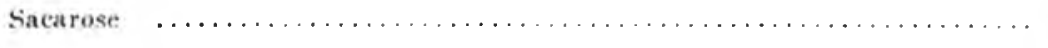 & $20 \mathrm{~g}$ \\
\hline Agun clistilada q. s. .... & $1000 \mathrm{nil}$ \\
\hline
\end{tabular}

Q13:I!RVIIGOHE

Deprois de retirado o envoltório da salsicha, juntar metade da água e moer em desintegrador elétrico ou em gral, formando pasta fina. Na outra metade da água se dissolvem os outros ingredientes; juntam-se as duas partes.

Acerlar o pIf para 6,2 a 6,6 .

Distribuir em tubos na quantidade de $15 \mathrm{ml}$ e esterilizar a 15 libras de pressño por 20 minutos.

l'or ocasiño do uso, aquecer o lubo contendo o meio em hanho-maria até fusão di ágar. Homogeneizar por movimentos rotalúrios e despejar o conteúdo em platca de Petri estéril. Deixar solidilicar, semear o material e incubar em estufa a 30-31"C em atmosfera saturada de umidade.

Sris a oito horas apos a scmeadura, caso for de origem microhiana o agente respolixácl pelas manchas, haverá formagão de un sombrcamento esverdicado acompanhando as estrias da semeadura.

Todos os cxames por nús feitos foran: sempre confirmados. Fste meio também serve paia o crescimento de colônias mucosas, indicando, então, formaऽão de polisacarídeos a partir da sacurose.

\section{RESLIIO}

() A.A. descrevem um meio de cullura capaz de, em 8 a 12 horas, estabelecer a nalureza das manchas de côr verde $\mathrm{cm}$ produtos de salsicharia, indicando, dıssa forma, se a altcração é devida a uma causa química ou microbiana. 
In this paper the A.A. devise a special medium which within 8.12 hours permits to assure if the green sausage discoloration is of microbial or chemical origin. This is accomplished because if the green discoloration is due to mentiers of the Lactobacillus group a green spot will appear at full length of the sulear.

The main advantage of the devised medium is that it reduces the time required for the presumptive test. 